\title{
O Assédio Moral no Contexto Universitário: uma
} DISCUSSÃo NECESSÁRIA

\author{
Workplace Bullying in the University Context:
}

a necessary discussion

\section{Thiago Soares Nunes}

Doutorando em Administração pelo Programa de Pós-Graduação em Administração da Universidade Federal de Santa Catarina.

Florianópolis, SC. Brasil. E-mail: adm.thiagosn@gmail.com

\section{Suzana da Rosa Tolfo}

Doutora em Administração (PPGA/UFRGS). Universidade Federal de Santa Catarina. Florianópolis, SC. Brasil. E-mail: srtolfo14@gmail.com

\section{Resumo}

O presente artigo tem por objetivo apresentar parte dos resultados de um projeto de pesquisa, que possibilitou identificar a ocorrência e as características de assédio moral no trabalho em uma universidade. A pesquisa foi classificada como descritiva e estudo de caso, com abordagem quantitativa e qualitativa. Foram enviados questionários aos servidores da universidade e realizadas entrevistas. Constatou-se que as universidades não estão imunes à ocorrência desse tipo de violência e que essas ocorrências causam transtornos para a saúde, sobretudo a mental, desses trabalhadores, pelo fato de ter implicado na deterioração das condições de trabalho, no isolamento e na recusa de comunicação, bem como em violências verbais, físicas ou sexuais. Conclui-se que a universidade deve criar e desenvolver medidas de prevenção e combate ao assédio moral, visto que as ações atuais têm sido ineficazes.

Palavras-chave: Assédio Moral no Trabalho. Universidade. Servidores.

\section{Abstract}

This article aims to present some results of a research project, which made possible to identify the workplace bullying occurrence and characteristics in a university. The research was classified as descriptive, case study, with quantitative and qualitative approach. Questionnaires were sent to the university servants, and interviews were conducted. It was found that universities aren't immune to the occurrence this kind of violence, and that cause health disorders, especially mental, which those workers, by the fact that implicated in the deterioration of working conditions, isolation and communication refusal, as well as verbal, physical or sexual violence. It's concluded that the university must create and develop measures to prevent and combat workplace bullying, since current actions have been ineffective.

Keywords: Workplace Bullying. University. Government Servants. 


\section{INTRODUÇÃO}

A ocorrência da violência dentro do universo laboral não é algo recente, contudo, observa-se, ao mesmo tempo, uma intensificação em função, principalmente, da divulgação da mídia e do interesse de pesquisadores de diferentes áreas do conhecimento no estudo deste fenômeno, bem como uma banalização da questão em função da imprecisão e generalização conceitual. Assim, embora seja difícil de ser conceituada, para fins deste artigo, compreende-se a violência como

[...] qualquer tipo de comportamento agressivo ou abusivo que possa causar um dano ou desconforto físico ou psicológico em suas vítimas, sejam essas alvos intencionais ou envolvidas de forma impessoal ou incidental. (WARSHAW, 1998, p. 51-52)

Entre as violências perpetradas no ambiente de trabalho, destaca-se o assédio que pode ser identificado no âmbito laboral mediante a caracterização de condutas abusivas e humilhantes nos relacionamentos interpessoais, as quais são intensificadas pelo aumento da competitividade entre os trabalhadores, por uma cultura organizacional permissiva ou incentivadora de práticas hostis em detrimento ao alcance das metas/ objetivos organizacionais, pelos estilos de liderança e formas de gestão (NUNES; TOLFO, 2012b). Portanto, o assédio moral pode ser identificado pela exposição do trabalhador, de forma repetitiva, a situações constrangedoras e humilhantes durante o exercício de sua função, caracterizado por uma ação, comportamento $e$ atitude violenta, desumana e antiética nas relações de trabalho (BARRETO, 2006). O assédio moral é considerado uma violência silenciosa e sutil, pois quem passa por ele muitas vezes não consegue identificar a violência, a intenção $e$ perversão do agressor. (HIRIGOYEN, 2006; 2008)

$\mathrm{O}$ assédio moral se manifesta independente do setor ou área, embora exista locais em que a violência é mais frequente, como o setor da saúde e da educação (HIRIGOYEN, 2006). Portanto, dividido em seis seções, busca-se no presente artigo, inicialmente apresentar alguns elementos que possibilitam compreender que o assédio moral no trabalho origina-se e vincula-se aos modos de organização da sociedade capitalista. Posteriormente, destaca-se as concepções de assédio moral e suas principais características. E, seguido da delimitação do método da pesquisa, apresenta-se parte dos resultados obtidos um projeto de pesquisa que teve como lócus de estudo o ambiente educacional de nível superior, em que se buscou identificar a ocorrência e as características de assédio moral no trabalho dos servidores docentes e técnico-administrativos de uma universidade. $\mathrm{O}$ artigo finaliza com as considerações finais e principais contribuições da pesquisa onde parte-se do pressuposto que por ser uma organização pública e de formação de profissionais de diversas áreas de conhecimento, as universidades devem consolidar-se como agentes comprometidos com o bem-estar de seus trabalhadores e em práticas de gestão éticas que respeitem os valores e costumes alheios.

\section{Reestruturação Produtiva}

Após um longo período de acumulação de capitais, durante o fordismo e a fase keynesiana, o capitalismo a partir dos anos de 1970, começou a dar os primeiros sinais do que pode ser chamado de crise estrutural do capital (ANTUNES, 2005). Essa crise estrutural, por sua vez, teve como expressão o neoliberalismo e a reestruturação produtiva da era da acumulação flexível (ou toyotismo), como resposta à crise do capital, repercutindo nas transformações do mundo do trabalho ${ }^{1}$ que vêm acompanhadas de profundas mudanças nas relações entre Estado e sociedade civil. Busca-se, neste sentido, uma flexibilidade nas estratégias de produção e nas condições de trabalho, em contrapartida à rigidez da produção em massa e em série, sendo esta mudança acompanhada da desregulamentação dos direitos conquistados pela classe trabalhadora e de novas formas de gerir recursos humanos.

Em síntese, a "flexibilização" do capitalismo tardio, levando a "classe-dos-que-vivem-do-trabalho" à defensiva e penalizando duramente a esmagadora maioria da sociedade, não resolveu nenhum dos problemas fundamentais postos pela ordem do capital. Mas ainda: diante da magnitude hoje atingida por esses problemas $[. .$.$] todas as indicações sugerem que o$ capitalismo "flexibilizado" oferecerá respostas dominantemente regressivas, operando na direção de um novo barbarismo, de que as atuais formas de apartheid social são premonitórias. (NETTO, 1996, p. 102) 
Essas mudanças ocorridas no mundo do trabalho passaram a exigir um perfil de trabalhador com alto índice de escolaridade, flexível, autônomo e polivalente - exercendo várias funções e, com isso, intensificando sua carga de trabalho e seu processo de desgaste físico e mental. Ou seja, tais mudanças instauram nos sujeitos "[...] uma necessidade quase irrefreável de buscar no mercado um 'pacote' de competências desejadas pelo mundo do trabalho, pois isso garantia a empregabilidade". (SOUZA; AZEREDO, 2004, p. 51)

No atual estágio de desenvolvimento tecnológico, faz-se menção também a tentativa de se obter o controle da produção e, consequentemente, mascarar as desigualdades e a exploração de uma classe sobre a outra inerente à sociedade capitalista, a partir da defesa da adesão do trabalhador às metas de produtividade. Ou seja, eles passam a ser chamados de "colaboradores", de "funcionários do mês", já que, a partir da competitividade, buscam auferir mais lucro que os demais. Dejours (2007), ao tratar do que é contemporâneo em relação à economia, ao trabalho e ao sujeito que trabalha, faz menção à busca desenfreada pela competitividade, em que associa a impossibilidade de empregar-se e reempregar-se com a geração de um processo de dessocialização continuado, à medida que põe em perigo a identidade de indivíduos ou grupos, bem como gera-se sofrimento para os que não têm trabalho e para aqueles que trabalham.

Dentre as consequências que a reestruturação produtiva acarreta, salienta-se, também, a flexibilização dos contratos de trabalho, a desregulamentação de direitos sociais, o desemprego estrutural e a diminuição dos postos de trabalho, explicado pela "necessidade do capital" de reduzir gastos, bem como pelas mudanças advindas da crise econômica aliada às radicais mudanças tecnológicas. Ou seja, presencia-se, cada vez em maior escala, segmentos da população caracterizados como "reserva", "descartáveis" para o mercado de trabalho. Contudo, é importante não perder de vista que este exército industrial de reserva é condição fundamental para a permanência do regime do capital.

Com base nas questões pontuadas, afirma-se que é neste cenário de precarização das relações laborais, de pressões por produtividade, competividade, que o assédio moral se faz presente e se intensifica desde os primórdios das relações trabalhistas (BARRETO, 2003). As relações estabelecidas na sociedade capita- lista produzem um ambiente fértil para o sofrimento do trabalhador, sendo esta questão visível no crescente número de pesquisas que apontam os efeitos da globalização e liberação de mercados, a busca crescente pela eficiência, a intensificação do trabalho e a confiança em sistemas de recompensa, como mudanças que podem conduzir ao aumento da ocorrência de assédio e conduta abusiva, que trazem consequências para a saúde, principalmente mental, do trabalhador. (SALIN, 2003; HIRIGOYEN, 2006)

Alguns autores, como inicialmente Marie-France Hirigoyen, trabalha a questão do assédio moral como uma situação essencialmente individual. No entanto, a temática é muito mais complexa, ou seja, deve-se considerar "[...] o indivíduo como um produto de uma construção sócio-histórica, sujeito e produtor de inter-relações que ocorrem dentro do meio-ambiente social, com suas regras e leis" (HELOANI, 2004, p. 2). Sendo que o sujeito é influenciado pela organização, que está dentro de uma lógica macroeconômica.

Assim, para melhor compreender o que vem a ser assédio moral, na seção a seguir apresentam-se concepções sob o ponto de vista de diferentes pesquisadores.

\section{Assédio Moral no Trabalho}

A temática do assédio moral veio à tona com a publicação do livro intitulado The Harassed Worker de Carroll Brodsky em 1976, entretanto, o livro ganhou destaque anos depois com o interesse crescente sobre o tema (BESWICK; GORE; PALFERMAN, 2006). Apesar do pioneirismo de Brodsky, as pesquisas e ideias do alemão Heinz Leymann sobre o assédio moral iniciadas em 1980, foram divulgadas e adotadas em vários países, em que este passou a ser considerado o precursor dos estudos empíricos sobre o tema (VARTIA, 2003). Logo, a conscientização da sociedade e dos acadêmicos, cresceu gradualmente nos países europeus a partir de 1990 (VARTIA, 2003) e em curto período de tempo o interesse popular cresceu rapidamente, provocando a divulgação em diversas mídias de casos de maus-tratos e violências no ambiente de trabalho. (ZAPF; EINARSEN, 2005)

O assédio moral envolve comunicação hostil $e$ não ética, direcionada de um modo sistemático por um ou mais indivíduos para um alvo que, durante 
essa violência, é posto em uma posição desamparada e indefesa, sendo mantido nesta condição por meio de ações hostis (LEYMANN, 1990; 1996). Einarsen et al. (2005) definem o assédio moral no trabalho como ações e práticas repetidas, dirigidas a um ou mais trabalhadores de forma consciente ou inconsciente, que são indesejados pela vítima, e causam humilhação, ofensa e angústia, além de poder interferir no desempenho do trabalho e/ou tornar o ambiente de trabalho desagradável.

No Brasil, a francesa Marie-France Hirigoyen foi a principal responsável pela popularização do tema, por meio da publicação dos livros "Assédio moral: a violência perversa no cotidiano" e posteriormente "Mal-estar no trabalho: redefinindo o assédio moral". O assédio moral para Hirigoyen (2006) remete a condutas abusivas, manifestas por comportamentos, gestos, palavras, atos e escritos que podem causar danos à saúde (física e/ou psíquica) do indivíduo, por em perigo seu emprego e ainda degradar o ambiente de trabalho. Os pesquisadores brasileiros mais representativos são Margarida Barreto, Roberto Heloani e Maria Ester de Freitas. Além de diversos artigos científicos e trabalhos publicados sobre o tema, estes três pesquisadores lançaram em 2008 o livro intitulado Assédio Moral no Trabalho, que apresenta informações extremamente relevantes sobre o tema, sua definição, características, consequências e demais assuntos relacionados. Nesse sentido, os autores conceitualizam o assédio moral no trabalho como uma conduta intencional e abusiva, frequente e repetida, que ocorre no âmbito de trabalho com intuito de humilhar, diminuir, constranger, desqualificar e demolir psiquicamente um indivíduo ou um grupo, degradando as suas condições de trabalho, atingindo sua dignidade e colocando em risco a sua integridade profissional e pessoal. (FREITAS; HELOANI; BARRETO, 2008)

Os estudiosos do tema, conforme exposto anteriormente, apresentam definições e classificações muito similares e até complementares. Doravante, há aspectos distintivos que auxiliam na caracterização do assédio moral, a saber:

a) Intencionalidade: a violência neste caso pode surgir de forma consciente ou inconsciente. O caráter consciente da violência é defendido por Heloani (2005), Freitas, Heloani e Barreto (2008) e Schatzmam et al. (2009). Contudo, autores como Leymann (1990; 1996), Einarsen et al. (2003; 2005) e Nunes e Tolfo (2012a; $2012 b)$, ressaltam que as práticas hostis/violentas podem ser inconscientes. Apesar do caráter inconsciente da intencionalidade, isso não diminui a violência perpetrada nem o dano sofrido pela vítima.

b) Direcionalidade: voltada a um alvo em específico ou a um grupo.

c) Frequência e Duração: nos estudos de Leymann $(1990 ; 1996)$ para que o assédio moral fosse caracterizado era preciso ter uma frequência mínima de uma vez por semana $e$ um período de duração mínima de seis meses (LEYMANN, 1990; 1996). No entanto, o estabelecimento de um período mínimo é muito discutido entre os autores. De fato o assédio moral não é um evento isolado (isso se configura como dano moral), ele se caracteriza como uma pratica frequente e repetitiva, sendo que de forma geral há um consenso entre pesquisadores que o assédio se configura mais como uma questão de meses $e$ anos do que dias $e$ semanas. (EINARSEN et al., 2011)

d) Desequilíbrio de poder: situações de antagonismo nas quais a capacidade de ataque/defesa de cada um é desigual, mesmo entre indivíduos com funções equivalentes, com mesmo status social e de poder na organização. Portanto, não remete, necessariamente, à posição hierárquica ou socioeconômica dos indivíduos envolvidos na situação (SCHATZMAM et al., 2009), pode ocorrer também quando um tem: poder de reter recursos/ferramentas essenciais para o outro exercer sua função; poder de reconhecer vulnerabilidades de um indivíduo e explorar esse conhecimento em detrimento da pessoa; poder de segurar informação/conhecimento; o poder de usar o seu relacionamento com alguém para prejudicar e/ou ameaçar os outros.

e) Caráter processual: o assédio moral não é um fato pontual, mas um processo que evolui gradativamente (EINARSEN et al., 2003). O caráter processual do assédio moral muda conforme o passar do tempo e as mudanças sociais. A violência pode começar por situações veladas, ditas "brincadeiras", e "evoluírem" para algo mais violento e visível.

A partir das características supracitadas para classificação do assédio moral, segue-se com a catego- 
rização das situações hostis tendo como base Hirigoyen (2006). Tal classificação permite uma visualização mais ampla das diversas situações.

a) Deterioração Proposital das Condições de Trabalho: agir de maneira a fazer o alvo parecer incompetente, como: contestar sistematicamente as decisões por ele tomadas, induzir o alvo ao erro, repassar instruções impossíveis de serem seguidas, críticas exageradas e injustas em relação ao seu trabalho, dentre outras. Tais situações são geralmente oriundas dos superiores hierárquicos. (HIRIGOYEN, 2006)

b) Isolamento e Recusa de Comunicação: comportamentos com intuito de constranger $e$ maltratar o outro, tais como: comunicar-se com a pessoa somente por escrito, deixar de fora de uma conversa, evitar contato (até visual), interromper a pessoa constantemente, recusar falar-lhe, não convidá-lo para reuniões, entre outros. As ações e os comportamentos nesta categoria, geralmente, são praticados tanto por colega de mesmo nível hierárquico quanto por superiores.

c) Atentado Contra a Dignidade: são gestos de desprezo, insinuações desqualificadoras $e$ chacotas, que geralmente são reparadas por todos, contudo, o alvo é considerado responsável. O agressor utiliza-se de insinuações desdenhosas para desqualificar o alvo, criticar sua vida pessoal, zombar de suas origens, nacionalidade e outros. As práticas destas hostilidades são frequentemente proferidas por colegas que invejam o alvo.

d) Violência Verbal, Física ou Sexual: aparece quando o assédio está declarado e é visível a todos. Nesta categoria, acontecem ameaças de violência física, empurrões, gritos injuriosos, assédio sexual, enfim, violências que repercutem também para fora do âmbito de trabalho, com telefonemas noturnos e cartas anônimas, por exemplo.

O agrupamento das situações hostis é fundamental para conhecer as principais formas e manifestações da prática desta violência. Verifica-se na classificação de Hirigoyen (2006) que a primeira categoria - Deterioração Proposital das Condições de Trabalho contém ações, comportamentos e atitudes, ditas sutis, que se não bem identificadas podem ser consideradas "normais" ou brincadeiras dentro do ambiente de trabalho, escondendo assim o seu caráter perverso. Já a categoria Violência Verbal, Física ou Sexual é a mais visível, e fácil de identificar.

As práticas hostis podem ter sua origem em diversas direções: vertical descendente (superior hierárquico), vertical ascendente (subordinado ao superior), horizontal (colegas) e misto. Incialmente as agressões podem advir de um superior hierárquico, e posteriormente de colegas de mesmo nível, tornando-se um assédio misto. No Brasil, o assédio descendente é o mais praticado, alcançando índices de $90 \%$ de ocorrência (BARRETO, 2005). No assédio descendente, segundo Hirigoyen (2006) há diversos subgrupos: a) assédio perverso: exercido com o objetivo da eliminação do outro ou a valorização do próprio poder, neste caso como uma forma de se engrandecer o superior sente a necessidade de rebaixar os demais; b) assédio estratégico: tem o intuito de forçar o alvo a pedir demissão, gerando assim um processo de dispensa sem "prejuízos" para a organização; c) assédio institucional: um instrumento/forma de gestão disciplinadora do coletivo. O assédio horizontal, proveniente de colegas de posição ou poder equivalente, "[...] é mais frequente quando estes disputam a obtenção de um mesmo cargo ou posição [...]" (HIRIGOYEN, 2006, p. 113), ou seja, quando a competição é acirrada e há inveja do outro.

Ressalta-se que a violência ocorre e tem seus efeitos de forma diferente dependendo do setor ou área. O locus desta pesquisa é o setor de educação, mais especificamente o meio acadêmico. Apesar de as instituições de ensino terem como pilares o ensino, a pesquisa e a extensão, existe a prática de situações perversas entre os indivíduos e grupos, características de assédio moral, motivadas principalmente pelo abuso de poder ou medo de perdê-lo e a inveja. Buendía (2003) afirma que as universidades são incubadoras de enfermidades do trabalho, entre elas o assédio moral e o burnout. Em pesquisa, o autor verificou que a estrutura organizacional das universidades favorece a ocorrência do assédio, uma vez que ela é obsoleta, rígida e extremamente burocratizada, com muitos espaços de poder, com poucas pessoas que detêm cargos importantes e se utilizam deles para se sobrepor aos demais (BUENDÍA, 2003). Ademais, nas universidades existe um sistema de apadrinhamento que gera relações de vantagens para alguns, enquanto os outros são alvos potenciais para o assédio (NUNES; TOLFO; NUNES, 2013). E, finalmente, a universidade deixa espaços 
para a impunidade e converte a submissão em uma condição necessária para adaptar-se.

Independentemente do setor de ocorrência do assédio é fundamental que a organização e seus gestores tenham como preocupação prevenir e combater a violência no âmbito de trabalho, por meio do estabelecimento de determinadas políticas que contribuam para a divulgação de informações básicas sobre o assédio moral com intuito de conscientizar tanto os superiores quanto subordinados em relação a esta violência, e também que destaquem quais medidas serão aplicadas mediante a identificação dela. A partir daí, com ações afirmativas, poderá inibir e diminuir a ocorrência do assédio moral no ambiente organizacional e desenvolver uma gestão mais social do que instrumental. Entidades públicas e privadas, cada vez mais, adotam padrões de gestão que estimulam atitudes competitivas, individualistas e aéticas nas relações de trabalho, colocando-se na contramão da luta por uma sociabilidade fundada em interesses coletivos, que defenda um projeto de sociedade com perspectiva emancipatória, em que a liberdade, equidade e justiça social constituam, de fato, direitos de todos/as os/as trabalhadores/as. (CFESS, 2011, p. 1)

\section{Método}

A pesquisa foi classificada como descritiva $e$ estudo de caso, com uma abordagem quantitativa $e$ qualitativa. Os métodos quantitativo e qualitativo não se diferenciam somente pela sistemática pertinente a cada um deles, mas, sobretudo pela forma de abordagem do problema (RICHARDSON et al., 2008). Com a abordagem quantitativa buscou-se descrever as ocorrências e as características do fenômeno no ambiente da universidade analisada. Já a abordagem qualitativa foi utilizada de forma a complementar e aprofundar as informações acerca do tema. A população da pesquisa foram os servidores docentes e técnico-administrativos, aproximadamente 4.865 servidores. A primeira parte da pesquisa (quantitativa) foi censitária, ou seja, abrangeu a totalidade dos componentes do universo.

Para a coleta dos dados, os dados quantitativos foram levantados pela aplicação de questionário on-line, divulgado para os servidores por e-mail e também por comunicação dos sindicatos de cada classe. O questionário, além de apresentar questões acerca do perfil do indivíduo e de trabalho do pesquisado, incluiu questões sobre assédio moral, na forma de uma lista de situações hostis tendo como base o instrumento NAQ-R (Negative Acts Questionnaire-Revised), de autoria de Einarsen, Raknes, Matthiesen. As situações hostis foram ampliadas com o objetivo de aprofundarem melhor a realidade estudada. Além dessas questões, há também perguntas sobre os agressores, consequências, bem como articulação do tema com a instituição em si. Já os dados qualitativos foram coletados por meio de entrevistas com sujeitos que se disponibilizaram ao responderem o questionário on-line, para participar de entrevista com intuito de aprofundar as informações pertinentes ao tema, utilizando-se para isso um roteiro predefinido.

Em relação à interpretação e à análise dos dados, as informações obtidas por meio do questionário on-line foram tratadas por um software estatístico denominado SPSS (Statistical Package for the Social Sciences) seguindo uma abordagem de análise quantitativa. Como forma de compreender melhor o fenômeno, no que tange às situações hostis, estas foram agrupadas em quatro categorias seguindo classificação de Hirigoyen (2006) já apresentadas neste artigo: a) Deterioração Proposital das Condições de Trabalho; b) Isolamento e Recusa de Comunicação; c) Atentado Contra a Dignidade; d) Violência Verbal, Física ou Sexual. As entrevistas foram analisadas por meio da análise de conteúdo, em que a partir das transcrições realizadas elaborou-se um quadro para analisar as informações proferidas pelos entrevistados. Por fim, a partir da análise dos dados quantitativos e qualitativos e da literatura, foi possível fazer a triangulação dos dados, conforme será exposto em sequência.

\section{Apresentação e Análise dos Dados}

Os respondentes ${ }^{2}$ da pesquisa, 279 participantes, são $55,9 \%$ do sexo feminino e $43 \%$ do sexo masculino, com média de idade de 45 anos. Em sua maioria, o grupo é de etnia branca $(88,2 \%)$, com estado civil união estável ou casado $(64,2 \%)$ e com formação de Pós-Graduação em nível de Doutorado (57\%). Em relação aos dados contratuais, $60,9 \%$ são servidores docentes e $36,6 \%$ são servidores técnico-administrativos. Destes, $54,1 \%$ têm Dedicação Exclusiva e $41 \%$ trabalham em regime de 40h, com uma renda mensal entre 10 a 14 salários mínimos ( $\mathrm{R} \$ 5.101$ a $\mathrm{R} \$ 7.140), 23,7 \%$ dos 
pesquisados. Sobre o tempo de instituição, $25,8 \%$ trabalham há mais de 25 anos na instituição, 15,8\% trabalham entre 1 a 5 anos, e apenas 7,9\% estão a menos de um ano. Sobre a lotação/vínculo do servidor na instituição, $71 \%$ estão vinculados a Centros de Ensino, $12,6 \%$ na Reitoria (incluídos aqui as Pró-Reitorias, e órgãos suplementares, como o Hospital Universitário e a Agência de Comunicação) e 3,9\% em Secretarias. Em relação aos sete entrevistados, qautro são do sexo feminino e três do sexo masculino, quatro servidores técnico-administrativos e três servidores docentes, seis possuem pelo menos uma Pós-Graduação, cinco trabalham em Centros de Ensino e dois em Pró-Reitorias, três trabalham entre um a cinco anos na instituição, dois entre 15 a 20 anos, um entre cinco e dez anos e um trabalha a mais de 25 anos.

\subsection{Ocorrência do Assédio Moral: descrição das situações hostis}

Conforme exposto no método, as situações hostis foram categorizadas tendo como base a classificação de Hirigoyen (2006). Foram elaborados quadros-resumos de cada categoria, os quais contêm as situações hostis com maior frequência obtidas por meio do questionário em consonância com as situações identificadas nos discursos dos entrevistados. Ou seja, nesses quadros apenas serão apresentadas as situações com maior frequência, tanto nos questionários quanto nas entrevistas.

\begin{tabular}{|c|c|c|}
\hline Deterioração Proposital das Condições de Trabalho & QuestionÁrios & ENTREVISTAS \\
\hline Foi exposto a uma carga de trabalho excessiva & $13,7 \%$ & 2 e 6 \\
\hline Foi obrigado a realizar uma atividade abaixo do seu nível de competência & $9 \%$ & 6 \\
\hline Houve supervisão excessiva de seu trabalho & $5 \%$ & 6 \\
\hline Agiram de modo a impedir que obtenha promoção & $3,3 \%$ & 5,6 e 7 \\
\hline Privaram-lhe acesso aos instrumentos de trabalho: telefone, computador, etc. & $2,5 \%$ & 3 e 7 \\
\hline Isolamento E Recusa de Comunicação & QuestionáRIOS & ENTREVISTAS \\
\hline Ignoram sua presença & $8,6 \%$ & 3 e 5 \\
\hline Superiores hierárquicos ou colegas não dialogam com você & $7,9 \%$ & $3,4,5$ e 7 \\
\hline Suas opiniões e pontos de vista foram ignorados & $6,5 \%$ & 2,4 e 7 \\
\hline Foi recebido com uma reação hostil quando você se aproximou & $5,1 \%$ & 2 \\
\hline Atentado Contra a Dignidade & QuestionÁRIOS & ENTREVISTAS \\
\hline Espalharam boatos ou rumores sobre você & $7,6 \%$ & 3,4 e 6 \\
\hline Foi humilhado ou ridicularizado em relação ao seu trabalho & $4 \%$ & $2,3,5,6$ e 7 \\
\hline Foram feitos comentários ofensivos e insultos sobre suas atitudes e comportamentos no trabalho & $3,2 \%$ & $2,3,4,6$ e 7 \\
\hline Foi submetido a excessivas provocações e sarcasmos & $2,9 \%$ & 2 e 7 \\
\hline ViolênCia Verbal, Física ou Sexual & QuestionÁRIOS & ENTREVISTAS \\
\hline Foi alvo de agressividade (ou raiva) gratuita & $3,9 \%$ & 5 e 6 \\
\hline Foi ameaçado com ligações telefônicas, cartas, e-mail ou outras formas & $1,8 \%$ & 3 \\
\hline $\begin{array}{l}\text { Foi alvo de comportamentos intimidativos, tais como apontar o dedo, inva- } \\
\text { são do seu espaço pessoal, empurrões, bloqueio de seu caminho }\end{array}$ & $1,4 \%$ & 5 e 6 \\
\hline
\end{tabular}

Quadro 1: Frequência das situações hostis nas categorias

Fonte: Dados primários 
Na categoria Deterioração Proposital das Condições de Trabalho, as estratégias dos agressores podem criar condições que favoreçam o fracasso do indivíduo, ao ressaltar seus erros e omissões ou até destiná-lo apenas a atividades de baixa complexidade, o que diminui a probabilidade do reconhecimento social de seu grupo de trabalho. As situações destacadas no Quadro 1, de forma geral, são estratégias hostis executadas por superiores hierárquicos, ou seja, há o abuso de poder destes com objetivo de desqualificar e prejudicar o outro. Segundo Heloani (2004, p. 2), a "[...] humilhação está embasada no próprio sistema macroeconômico, que, em seu processo disciplinar, favorece o aparecimento dessa forma de violência, em que o superior hierárquico detém um certo poder sobre seu subordinado [...]", o que lhe "permite", em determinados casos, utilizar estratégias para aumentar a produtividade. Assim, o abuso de poder pode ser uma estratégia constante para prejudicar e eliminar aquele que pode ser um obstáculo para o perpetrador. (SALIN, 2003; EINARSEN, 2005)

A Recusa da Comunicação é uma maneira de agredir o alvo, demonstrar que ele não interessa ou não existe para o agressor, e, como o agressor, nesta situação, "não usa palavras", fica mais fácil de ser repreendido (HIRIGOYEN, 2008; FREITAS, 2001). Essa violência tem como objetivo destruir as redes de comunicação do alvo de modo a persuadi-lo a abandonar o seu emprego (LEYMANN, 1990). Devido à sutileza dessas estratégias, elas podem permitir o anonimato do agressor por mais tempo, podendo até impossibilitar a sua identificação.

No Atentado Contra a Dignidade, os boatos, rumores e mentiras são condutas que limitam a possibilidade das vítimas manterem contatos sociais, de modo que pode provocar o afastamento dos demais (LEYMANN, 1990). Nas agressões verbais, sarcasmos, zombarias e cinismos, há também certo jogo, pois conforme afirma Hirigoyen (2006), para o agressor existe o prazer da polêmica, de levar a vítima a opor-se.

As situações da categoria Violência Verbal, Física ou Sexual, não apresentam um caráter sutil como nas outras categorias apresentadas anteriormente, assim são mais facilmente identificadas (HIRIGOYEN, 2006). Ou seja, fica evidente pelas situações destacadas no Quadro 1 a intenção do agressor em agredir a vítima, mediante ações e comportamentos intimidativos, muitas vezes com objetivo de se sobrepor ao alvo mostrando seu poder e/ou fazer com que ela sinta-se ameaçada e peça demissão.

Após a análise individual das situações hostis em cada categoria, buscou-se identificar o percentual da ocorrência de assédio moral por categoria, conforme segue na Tabela $1 \mathrm{com}$ a apresentação dos dados de forma resumida.

Tabela 1: Resumo da ocorrência das categorias

\begin{tabular}{|c|c|c|c|c|c|c|}
\hline SituAÇÕES & $\begin{array}{c}\text { SEM RES- } \\
\text { POSTA }\end{array}$ & Nunca & $\begin{array}{c}\text { DE VEZ EM } \\
\text { QUANDO }\end{array}$ & Mensalmente & Semanalmente & Diariamente \\
\hline $\begin{array}{c}\text { Deterioração Proposital das } \\
\text { Condições de Trabalho }\end{array}$ & $3,4 \%$ & $69,1 \%$ & $20 \%$ & $2,9 \%$ & $1,7 \%$ & $2,9 \%$ \\
\hline $\begin{array}{l}\text { Isolamento e Recu- } \\
\text { sa de Comunicação }\end{array}$ & $3,5 \%$ & $68,8 \%$ & $19,6 \%$ & $3 \%$ & $1,9 \%$ & $3,2 \%$ \\
\hline Atentado Contra a Dignidade & $3,7 \%$ & $72,4 \%$ & $17,8 \%$ & $2,5 \%$ & $1,3 \%$ & $2,4 \%$ \\
\hline Violência Verbal, Física ou Sexual & $3,6 \%$ & $85 \%$ & $8,9 \%$ & $1,1 \%$ & $0,7 \%$ & $0,7 \%$ \\
\hline
\end{tabular}

Fonte: Dados primários

Conforme a definição de Leymann (1990; 1996), só pode ser considerado assédio moral se a situação hostil ocorreu com frequência mínima de uma vez por semana, desse modo, apenas as situações assinaladas com frequência "Semanalmente" ou "Diariamente" foram categorizadas como assédio moral. A incidência de assédio moral nas categorias foi assim distribuída: "Deterioração Proposital das Condições de Trabalho" (4,6\%), "Isolamento e Recusa de Comunicação" (5,1\%), "Atentado Contra a Dignidade" (3,7\%), e "Violência Verbal, Física ou Sexual" (1,4\%). 
A história dos países latino-americanos é permeada pela via da dependência, expropriação, subalternidade, em função da incorporação dos preceitos do capitalismo: a contradição entre capital $x$ trabalho. Nesse ínterim, a classe trabalhadora é submetida à perversa contradição no processo de acumulação capitalista, tais como a superexploração, que abrange situações como: desemprego estrutural, aumento da jornada de trabalho, precarizações na forma de contratação, baixa remuneração, flexibilização das relações trabalhistas, dentre outras que estão diretamente relacionadas à generalização, intensificação e banalização da ocorrência do assédio moral no ambiente laboral ${ }^{3}$.

Portanto, ao discorrer sobre o assédio moral na sua relação com o atual modo de produção, é possível ponderar que as novas configurações assumidas pelo mundo do trabalho, reforçam que a "[...] conjunção globalização mais neoliberalismo veio mostrar aos ingênuos que o capital não tem nenhum compromisso social". (NETTO, 2001, p. 47)

Contudo, na busca de mascarar suas contradições e transmitir a ideia de um "capitalismo humanizado" (naturalizando-o como único sistema econômico possível), é cada vez mais evidente o discurso da cooperação e trabalho em equipe. Neste caso, as empresas incitam que os funcionários trabalhem de forma coletiva com o intuito de gerar um ambiente "harmônico" e, com isso, auferir cada vez mais lucro. No entanto, para o Heloani (2005), esses elementos são antagônicos: a necessidade de cooperação em equipe e a competição pela aquisição e manutenção de um posto de trabalho.

Fica evidente que atualmente há uma predominância refletida na racionalidade instrumental, em que os fins justificam os meios e para alcançá-los utiliza-se de estratégias e ações muitas vezes não éticas. Ao relacionar tais questões à vida organizacional e seus afluentes, percebe-se a busca incessante pelo lucro, a superexploração do trabalhador, e um ambiente laboral de rivalidades e intrigas. Tais fatores são influenciados pela cultura local e organizacional, e também por aspectos econômicos, até porque o sistema capitalista é influenciador direto para a ocorrência do assédio moral no trabalho.

\subsection{A Violência: identificação e "perfil" dos agressores}

Posteriormente à lista de situações hostis, analisada anteriormente, questionou-se ao pesquisado se ele se identificava como vítima de assédio moral nos últimos seis meses. Verificou-se que apenas $27,6 \%$ (77 pesquisados) afirmaram serem vítimas de assédio moral, em contrapartida a $66,7 \%$ que não se percebem como alvos de situações hostis e 5,7\% não responderam. Contudo, é importante enfatizar que esse percentual pode não corresponder à realidade, uma vez que por falta de conhecimento do tema e pela sutileza dos comportamentos e ações hostis, o alvo pode considerar tais situações como "normais" dentro do ambiente de trabalho (EINARSEN et al. 2003; 2005; FREITAS; HELOANI; BARRETO, 2008). As análises seguintes terão como norte os dados obtidos apenas dos sujeitos que se identificaram como vítimas de assédio (77 pesquisados).

As agressões foram originadas quase que igualmente por colegas de mesmo nível hierárquico $(45,5 \%)$ e superiores hierárquicos $(44,2 \%)$, contudo, foram identificados casos da prática de assédio por parte de subordinados $(2,6 \%)$ e pessoas externas à organização $(3,9 \%)$. De modo geral, prevalece na literatura dados em que as agressões partem, majoritariamente, dos superiores (HIRIGOYEN, 2006; 2008; VARTIA, 2003). Em relação ao gênero dos agressores, identificou-se que são praticadas, em sua maioria, por homens $(41,6 \%)$, seguidas por homens e mulheres $(33,8 \%)$ e por mulheres $(23,4 \%)$. Em sua maioria $(70,2 \%)$, os respondentes afirmam que pelo menos duas pessoas estavam envolvidas nos comportamentos hostis.

A aceitação do "trabalho sujo" segundo metáfora de Dejours (2007) explica a participação consciente do sujeito em atos injustos como um ato calculista. Justificada, sobretudo, para manter seu lugar, conservar seu cargo, sua posição, seu salário e não comprometer o seu futuro na organização. Em muitas organizações, o indivíduo é incitado a partir de uma cultura organizacional, que objetiva o resultado acima de tudo, a utilizar-se de métodos, manipulações e atos para cum- 
prir suas metas, não se importando com a execução de práticas violentas para tal fim.

As exigências de metas, a competitividade nas organizações, pressão por parte dos diretores, entre outras manifestações, provocam nos trabalhadores inseguranças e grau de ansiedade que, em determinadas circunstâncias, influenciam na ocorrência de comportamentos violentos no ambiente de trabalho. A Organização Internacional do Trabalho (OIT), segundo Freitas (2007) alerta que a violência no ambiente de trabalho apresenta um crescimento exponencial em todo o mundo nas últimas décadas. Essa violência, muitas vezes, pode ser justificada pela questão do poder. Como mencionado, alguns indivíduos por medo de perder sua posição começam a praticar formas de violência ${ }^{4}$ com os colegas mediante o atropelamento da ética e da própria dignidade humana. (DEJOURS, 2007; HELOANI, 2005)

Na perspectiva de Marx, o sistema capitalista sempre apresentará uma relação dominante e dominado, sendo que o indivíduo passa a se submeter a essas violências por uma questão de subsistência, pois se ele sair, perderá o trabalho e consequentemente sua forma de sustento. Da mesma forma, se ele sair, outro o substituirá, uma vez que há um contingente de trabalhadores desempregados em busca de emprego (exército industrial de reserva).

\subsection{Comentar e/ou Denunciar a Violência Sofrida}

Ao serem questionados se comentaram sobre a violência para alguém e por que, $66,2 \%$ daqueles que se identificaram como vítimas de assédio moral comentaram sobre a violência. Dos que comentaram, $51 \%$ deles conversaram com colegas de trabalho, e identificaram como motivos: por desabafo, necessidade de apoio, com objetivo de obter ajuda ou conselhos, e demais. Há casos em que não houve comentário, conforme o discurso do Pesquisado 23 que relatou ter vergonha de falar sobre a situação. Muitas vezes o não comentário da situação vivenciada é justificada pela insegurança da vítima em se expor, tanto no ambiente de trabalho quanto na vida pessoal. (HIRIGOYEN, 2006; 2008)

O ato de denunciar a violência é uma ação que, a rigor, pode acarretar em processos administrativos, ou seja, é uma ação da vítima em buscar seus direitos em detrimento à violência sofrida. Desse modo, apenas $24,7 \%$ denunciaram a violência sofrida. Contudo, apesar da formalização das denúncias, os pesquisados relataram que nada foi feito, ou seja, não houve mudanças ou sanções ao assediador e as violências continuaram. Em contrapartida, 64,9\% não formalizaram queixa na instituição, uma vez que, de maneira geral, acreditam que nada mudará, podendo até aumentar a frequência. Há alguns pesquisados que não relatam a violência, pois "Nunca fiz nada porque estou em estágio probatório e tenho medo de perseguição (59)". Portanto, fica evidenciado pelos dados o descrédito por parte dos pesquisados na efetividade de análise e julgamento dos casos de assédio moral por parte da instituição. O motivo disso, segundo eles, é o corporativismo entre colegas, ou grupos dominantes, que utilizam de seu poder em prol de benefícios próprios ou para pessoas do grupo. As vítimas temem denunciar também por medo de alguma vingança ou sanção que poderia sofrer, como rebaixamento de cargo ou perda de chefia/gratificação, além do fato da repercussão, que as deixariam mais constrangidas e envergonhadas. (HELOANI, 2004)

Não obstante, o nexo causal (comprovação da relação entre a consequência, sofrimento da vítima; e a sua causa, a agressão) indispensável na esfera criminal, muitas vezes é invisível, uma vez que as agressões e humilhações são feitas de forma velada, "com luvas", sendo muito difícil reunir qualquer prova para denunciar. (HELOANI, 2005)

\subsection{Consequências e Efeitos da Violência para as Vítimas}

Os efeitos proporcionados pelo assédio podem ser severos, repercutem não somente na saúde física e/ou psíquica do trabalhador, mas afetam sua vida privada e desempenho organizacional. Além, é claro, de afetar a própria organização. Na pesquisa foram identificados efeitos psicológicos expressivos, segundo dados obtidos nos questionários e entrevistas, a saber: estresse, desânimo, desmotivação, isolamento, depressão, distúrbios de sono, irritação, raiva, nervosismo, baixa autoestima, frustração, tristeza, entre outros. No âmbito físico, constatou-se: perturbação/problemas físicos, dores de cabeça, adoecimento, aumento 
de peso, dores musculares, dores no peito e outros. Evidencia-se, portanto, que as consequências para o indivíduo assediado podem ser altamente destrutivas (LEYMANN, 1996), podendo chegar até ao suicídio. (BARRETO; VENCO, 2011)

Não obstante, ocorreram também efeitos no âmbito do trabalho, como: dificuldade de progressão profissional (Pesquisados 10 e 74), ameaças de mudança de setor (Pesquisado 66), vontade de abandonar o trabalho (Pesquisados 145, 190, 193 e 263), maior carga de trabalho (Pesquisado 109), e outras. Na vida privada foi identificado no discurso do Pesquisado 176 conflitos conjugais, levando até ao Pesquisado 74 ir à procura de acompanhamento de psiquiatra e psicólogos. As consequências e efeitos do assédio moral não ficam em torno do ambiente laboral, mas repercutem e afetam em aspectos da vida pessoal da vítima (NUNES; TOLFO, 2012a). A destruição da identidade do indivíduo vítima de assédio moral no trabalho ocorre rapidamente prejudicando, assim, o contexto de sua vida pessoal. No entanto, sua recuperação e inserção novamente na sociedade e no ambiente de trabalho pode levar anos. (MARTININGO FILHO; SIQUEIRA, 2008)

Dessa forma, as reivindicações em defesa da saúde do trabalhador devem ser incorporadas como principal aspecto das lutas dos trabalhadores, profissionais e gestores de políticas voltadas para o âmbito da saúde (LARA, 2011). Para o autor, atender a essa demanda é uma condição emergencial e de grande importância na construção de uma sociedade que no futuro permitirá aos trabalhadores terem saúde para o trabalho e para suas vidas. E que, a partir disso, terão uma vida repleta de sentido que transcenderá "[...] as amarras da exploração do trabalho como condição do desenvolvimento social. (LARA, 2011, p. 84)

\subsection{As Ações da Universidade em Relação ao Assédio Moral sob Percepção dos Pesquisados}

Os participantes e entrevistados também foram questionados sobre políticas e práticas de prevenção e combate ao assédio moral adotadas pela instituição. Os dados mais representativos foram os seguintes:

a) 56,3\% desconhecem a existência de orientações aos funcionários sobre o assédio moral na instituição; b) $81,4 \%$ relataram que não há treinamentos ou capacitações que abordam aspectos relacionados ao assédio moral;

c) $62 \%$ dos pesquisados não têm conhecimento (ouviu e/ou viu) sobre a divulgação da temática na instituição;

d) os que ouviram e/ou viram (24,7\%) identificaram como principais meios: mídias internas da universidade (jornais, cartilhas, cartazes, sites, lista de discussão) e por meio dos Sindicatos (técnico-administrativos e/ou docentes), ambos com $27,5 \%$ de ocorrência;

e) $80,6 \%$ afirmaram que não há uma política ou prática de prevenção e combate ao assédio;

f) a criação de uma política de prevenção $e$ combate ao assédio moral, já é um começo segundo $34,1 \%$ dos pesquisados; já 22,2\% afirmam que pode inibir um pouco a prática $e$ $21,5 \%$ relatam que funcionará se não acontecer corporativismo entre os colegas.

Evidencia-se que $47,7 \%$ dos pesquisados afirmaram que a prática de assédio é comum no ambiente universitário, sendo que tal dado está em consonância com o exposto por Hirigoyen (2006, p. 142), “[...] o meio educativo é um dos mais afetados pelas práticas de assédio moral". Para uma instituição, cujo objetivo é a geração e disseminação do conhecimento por meio do ensino, pesquisa e extensão, o desconhecimento por parte dos trabalhadores, a ausência de discussão do tema no ambiente universitário $e$ a falta de políticas $e$ práticas de combate, provocam um grande problema para prevenir a ocorrência dessa violência. Partindo do pressuposto de que o indivíduo não tem conhecimento sobre o tema (ou das próprias situações hostis), ele se torna incapaz de identificar se frequentemente é alvo de algumas situações e, consequentemente, de denunciar (NUNES; TOLFO, 2012b). E, sem a identificação da ocorrência do assédio, as instituições, por sua vez, podem avaliar, erroneamente, que não é pertinente e necessária a criação de mecanismos para coibi-lo.

Apesar de o assédio moral repercutir na produtividade e competitividade, nem todas as organizações desenvolvem políticas de prevenção e intervenção, em algumas o assédio constitui como uma estratégia para administrar o corpo funcional. Este é um caso quando existe pouco controle sobre o processo de trabalho devido a um "[...] baixo nível de organização e coordenação" (SIEGLIN, 2012). O assédio vertical, nesses 
casos, representa uma tentativa individual e abusiva para recuperar o controle. Contudo, a cultura organizacional não se encontra isolada da cultura política de um país, para a autora, o assédio constitui em muitas organizações latino-americanas como uma forma de controle primitivo dos trabalhadores e não está relacionada com o "caos organizacional". Ademais, como política de controle laboral o assédio não somente se direciona para as vítimas, mas também para demais trabalhadores que o observam, porém são impotentes para se manifestarem contra a violência.

O fato é que as organizações não são neuróticas, paranoicas ou perversas, seu modo de funcionamento que promove tais comportamentos. Nesse sentido, ela pode pôr em ação modos de gerenciamento que favoreçam a ocorrência de violência e assédio moral (GAULEJAC, 2007). O autor complementa que quando o assédio, estresse, depressão e demais sofrimentos psíquicos se desenvolvem e surgem na organização, é a própria gestão que deve ser questionada, pois, na maioria dos casos, o assédio não é o fato de um indivíduo em particular, mas de uma situação de conjunto.

Em relação às políticas e práticas, Salin (2008) advoga que o desenvolvimento destas pressupõe, necessariamente, em uma posição clara e coerente da gestão, participação ativa e envolvimento dos membros de diferentes funções e níveis hierárquicos, além dos sindicatos neste processo em prol dos direitos dos trabalhadores vítimas do assédio moral; somente deste modo esta política será transformada em práticas efetivas. Assim, a criação e aplicação de políticas e práticas inibidoras do assédio moral e orientadoras das relações interpessoais têm como o intuito, como o próprio nome sugere, coibir a prática, no entanto, são um ponto inicial, ou seja, não conseguirão abarcar a totalidade das situações que ocorrem na instituição, visto que estas acontecem sob conivência e/ou estimuladas pelas organizações e, consequentemente, pela mundialização do capital, reestruturação produtiva e competitividade que implicam novos arranjos e rearranjos que, por sua vez, perpassam todo o tecido social e apresentam consequências contundentes para os trabalhadores.

\section{Considerações Finais}

A lógica da sociedade capitalista globalizada, a busca por lucros, a cobrança de resultados, a precarização do trabalho, os contratos terceirizados, a tendência à contratação de projetos de prazo determinado e a existência de desemprego podem se constituir como elementos desencadeadores do crescimento, gravidade e amplitude do fenômeno do assédio moral no trabalho, significando um retrocesso aos direitos dos trabalhadores.

A compreensão da sociedade, da forma como ela se organiza, das suas fases, possibilita uma compreensão sobre a questão do assédio moral no trabalho. Ou seja, o capitalismo intensificou suas contradições e vem buscando atenuar as desigualdades com base na adesão de políticas de ajuste recomendados por entes como o Fundo Monetário Internacional (FMI), Banco Mundial em função do Consenso de Washington. Neste aspecto, com as restruturações produtivas, o trabalhador passou a ser submetido a diferentes formas de trabalho, sinaliza-se aqui principalmente a degradação e precarização das condições de trabalho presentes no fordismo/taylorismo, toyotismo, reestruturação da produção flexível, e no neoliberalismo, em que o trabalhador continuou sendo explorado. Mas, agora, essa exploração se intensifica, pois ele passa a que ser polivalente e competitivo, podendo acirrar as violências entre os trabalhadores, visto que estas mudanças instauram nos sujeitos "[...] uma necessidade quase irrefreável de buscar no mercado um 'pacote' de competências desejadas pelo mundo do trabalho, pois isso garantia a empregabilidade [...]" (SOUZA; AZEREDO, 2004, p. 51) ou uma maior aceitabilidade.

$\mathrm{O}$ assédio moral no trabalho é uma violência perversa e hostil, muitas vezes sutil e silenciosa, que dificulta a sua identificação e combate nos ambientes organizacionais. A ocorrência dessa violência no ambiente universitário não a torna menos nociva, uma vez que a estrutura universitária apresenta fatores que podem facilitar a ocorrência deste fenômeno (BUENDÍA, 2003; NUNES; TOLFO, 2012b). Nesse 
sentido, esta pesquisa teve como objetivo identificar a ocorrência e as características de assédio moral em uma universidade.

Ficou evidenciada a ocorrência do assédio moral na universidade, manifestada em suas diversas formas. Seguindo as categorias de Hirigoyen (2006) utilizadas nesta pesquisa, as frequências de ocorrência foram: "Deterioração Proposital das Condições de Trabalho" (4,6\%), "Isolamento e Recusa de Comunicação" (5,1\%), "Atentado Contra a Dignidade" (3,7\%), e "Violência Verbal, Física ou Sexual (1,4\%). As violências foram perpetradas por dois ou mais agressores $(70,1 \%)$; por colegas de trabalho $(45,5 \%)$; e por superiores hierárquicos $(44,2 \%)$, do sexo masculino (41,6\%). A universidade, segundo percepção dos pesquisados e entrevistados, não apresenta ações efetivas contra a prática do assédio moral. De modo que constatou-se que não há políticas de prevenção e combate $(80,6 \%)$, nem a inserção da temática nas capacitações e treinamentos $(81,4 \%)$, orientações aos funcionários sobre o assédio moral (56,3\%), divulgação do tema (62\%), entre outros.

Embora a percepção dos pesquisados em relação às ações da universidade seja, de maneira geral, negativa, há setores que abordam o tema em palestras ou até nos seus sites, em especial, um núcleo de pesquisa que vem elaborando pesquisas e desenvolvendo ações de prevenção e orientação na instituição, como a realização de seminário estadual de prevenção ao assédio moral, construções de folders informativos, atendimento psicológico às vítimas de assédio e demais ações. Evidencia-se que a pesquisa realizada apresentou subsídios para as ações do núcleo, uma vez que constatou, de forma quantitativa e qualitativa, a ocorrência da violência na instituição. Além do que, esta pesquisa proporcionou, de forma indireta, a discussão, compreensão e a popularização do tema entre os trabalhadores.

É importante ressaltar que o trabalho realizado teve como diferencial o locus de pesquisa uma universidade - um ambiente segundo Hirigoyen (2006) com elevados índices de assédio moral. Destaca-se que nesta pesquisa não foi apenas analisado a ocorrência e as características da violência, mas também os efeitos proporcionados pela violência nas mais diversas esferas (individual, vida pessoal e profissional), e também as ações da universidade. Ou seja, a pesquisa apresenta seções algumas vezes mais direcionadas ao âmbito das ciências humanas como a psicologia, e outras nas ciências sociais, como a administração. De modo, a ter um panorama mais amplo desse fenômeno tão complexo, e que pode ser estudado e pesquisado nas mais diversas ciências.

A pesquisa reforçou o pressuposto de Hirigoyen (2006) em relação à ocorrência do assédio no ambiente acadêmico ser promovido pela recusa de diferença e pela necessidade de poder, no entanto, um diferencial encontrado foi que no ambiente analisado os agressores foram em sua maioria do mesmo nível do agressor, ao contrário do que é exposto na literatura - geralmente o agressor é o superior. Não obstante, foi identificado em alguns casos que o pesquisado conseguiu compreender o que realmente é o assédio moral, podendo desta forma, entender atitudes que ocorrem no seu ambiente e, com isso, cobrar medidas para coibi-las.

A sociedade brasileira e mundial cada vez mais exige do Estado e das organizações princípios e valores éticos e também solidários, que são muitas vezes executados por ações sociais dentro e fora das organizações e entidades. Desse modo, como despertar as entidades e gestores governamentais, os empresários, os empregados, enfim, toda a sociedade, em relação a essa forma de violência tão severa e frequente contemporaneamente? O despertar, neste caso, implica na identificação em tempo real das diversas formas de violência, das consequências para vítima, agressor e organização. Bem como criar obstáculos à cidadania deliberativa como um contínuo da sociedade. O compromisso com a mudança, com a geração do bem-estar coletivo, com o respeito à pluralidade, e particularmente com a inclusão coletiva dos atores organizacionais é um desafio e o foco da gestão social, inclusive no tratamento de questões ligadas ao assédio moral. Além é claro, é necessária a construção de políticas que possam diminuir e coibir a prática do assédio. Ações como estas e muitas outras, algumas apresentadas neste trabalho, são fundamentais. Contudo, deve-se também orientar em relação à prática de valores e principalmente do princípio ético no ambiente de trabalho. A educação e a ética no trabalho e na vida são as medidas mais efetivas contra as violências no ambiente de trabalho, como é o caso do assédio moral.

Por fim, é importante lembrar que negar a ocorrência do assédio, é contribuir para torná-lo mais 
violento do que realmente já é. Cabe, portanto, à instituição e seus gestores, bem como à sociedade, trabalharem coletivamente em prol da construção de medidas de prevenção e combate, e principalmente do comprometimento dos trabalhadores - docentes e técnico-administrativos - e também alunos em relação a temas importantes como valores e ética no trabalho. Somente desse modo é que essa violência poderá ser efetivamente combatida e prevenida. Contribuindo de maneira direta e decisiva para uma nova forma de organização social, em que o cidadão adquire de fato a condição de sujeito e age direcionado ao bem-estar coletivo.

\section{REFERÊNCIAS}

ANTUNES, R. Os sentidos do trabalho. São Paulo: Boitempo, 2005.

\section{BARRETO, M. M. S. Reflexões sobre a violência moral} no mundo do trabalho. 2003. Disponível em: < http://www. prefeitura.sp.gov.br/secretarias/administração/servidores/dasat/ doc/vilo\%Eancia\%20no\%20trabalho\%20-\%20Margarida\%20 Barreto.pdf>. Acesso em: 15 maio 2010.

BARRETO, M. M. S. Assédio Moral: a violência sutil - Análise epidemiológica e psicossocial no trabalho no Brasil. 2005. 188f. Tese (Doutorado em Psicologia). Programa de Pós-Graduação em Psicologia Social, Pontifícia Universidade Católica, São Paulo, 2005.

BARRETO, M. M. S. Violência, saúde e trabalho: uma jornada de humilhações. São Paulo: EDUC, 2006.

BARRETO, M. M. S.; VENCO, S. Da Violência ao Suicídio no Trabalho. In: BARRETO, M. M. S.; NETTO, N. B.; PEREIRA, L. B. (Org.). Do assédio moral à morte de si: significados sociais do suicídio no trabalho. 1. ed. São Paulo: Matsunaga, 2011. p. 221-248.

BESWICK, J.; GORE, J.; PALFERMAN, D. Bullying at work: a review of the literature. Derbyshire, UK: Health and Safety Laboratory. 2006.

BUENDÍA, J. El mobbing en el centro de estudios.

Mobbing Opinion: boletín de noticias sobre acoso psicológico. 2003. Disponível em: <http:// mobbingopinion.bpweb.net/artman/publish/article_793. shtml >. Acesso em: 10 jun. 2012.
CFESS. Conselho Federal de Serviço Social. CFESS

Manifesta: assédio moral nas relações de trabalho. 2011.

Disponível em: <http://www.cfess.org.br/arquivos/cfess_ manifesta_assedioFINAL.pdf >. Acesso em: 15 abr. 2013.

DEJOURS, C. A banalização da injustiça social. Rio de Janeiro: FGV, 2007.

EINARSEN, S. et al. The concept of bullying at work: the European tradition. In: EINARSEN, S. et al. (Org.).

Bullying and emotional abuse in the workplace: international perspectives in research and practice. London: Taylor \& Francis, 2003. p. 3-30.

EINARSEN, S. et al. Workplace Bullying: individual pathology or organizational culture? In: BOWIE, V.; FISCHER, B. S.; COOPER, C. L. (Org.). Workplace violence: issues, trends, strategies. Devon: Willian Publishing, 2005. p. 229-247.

EINARSEN, S. et al. The concept of bullying and harassment at work: the European tradition. In: EINARSEN, S. et al. (Org.). Bullying and Harassment in the Workplace: developments in theory, research, and practice. London: Taylor \& Francis, 2011. p. 3-39.

EINARSEN, S. The nature, causes and consequences of bullying at work: The Norwegian experience. Pistes, Québec, v. 7, n. 3, 2005.

FREITAS, M. E. Assédio Moral e Assédio Sexual: faces do poder perverso nas organizações. Revista de Administração de Empresas, São Paulo: FGV, v. 41, n. 2, p. 8-19, 2001.

FREITAS, M. E. Cultura organizacional: evolução e crítica. São Paulo: Thomson Learning, 2007.

FREITAS, M. E.; HELOANI, J. R.; BARRETO, M. M.

S. Assédio moral no trabalho. São Paulo: Cengage Learning, 2008.

GAULEJAC, V. Gestão como doença social: ideologia, poder gerencialista e fragmentação social. São Paulo: Idéias \& Letras, 2007.

HELOANI, R. Assédio moral - um ensaio sobre a expropriação da dignidade no trabalho. RAE-eletrônica, [on-line], v. 3, n. 1, p. 1-8, 2004.

HELOANI, R. Assédio moral: a dignidade violada.

Aletheia, Canoas, n. 22, p. 101-108, 2005. 
HIRIGOYEN, M. F. Assédio moral: a violência perversa no cotidiano. 10. ed. Rio de Janeiro: Bertrand Brasil, 2008.

HIRIGOYEN, M. F. Mal-estar no trabalho: redefinindo o assédio moral. 3. ed. Rio de Janeiro: Bertrand Brasil, 2006.

LARA, R. As tendências de estudo sobre o mundo do trabalho no Serviço Social. In: VI SEMINÁRIO DO TRABALHO, 2008, Marília. Anais..., Marília, SP, 2008.

LARA, R. Saúde do trabalhador: considerações a partir da crítica da economia política. Revista Katálysis, Florianópolis, v. 14, n. 1, p. 78-85, 2011.

LEYMANN, H. Mobbing and Psychological Terror at Workplaces. Violence and Victims, New York, v. 5, n. 2 , p. 119-126, 1990.

LEYMANN, H. The Content and Development of Mobbing at Work. European Journal of Work and Organizational Psychology, London, v. 5, n. 2, p. 165184, 1996.

MARTININGO FILHO, A.; SIQUEIRA, M. V. S. Assédio Moral e Gestão de Pessoas: uma análise do assédio moral nas organizações e o papel da área de gestão de pessoas. Revista de Administração Mackenzie, São Paulo, v. 9, n. 5, p. 11-34, 2008.

\section{MARX, K. O capital: Crítica da economia política.} Livro primeiro: o processo de produção do capital. 2. ed. São Paulo: Nova Cultural, 1982. v. 1.

NETTO, J. P. Cinco notas a propósito da Questão Social. Revista Temporalis, Rio Grande do Norte, v. 3, n. 3, p. 41-50, 2001.

NETTO, J. P. Transformações societárias e Serviço Social. Revista Serviço Social \& Sociedade, São Paulo, n. 50, p. 87-132, 1996.

NUNES, T. S.; TOLFO, S. R. Assédio moral no trabalho: consequências identificadas por servidores docentes $e$ técnico-administrativos em uma universidade federal brasileira. Revista GUAL, Florianópolis, v. 5, n. 3, p. 264-286, 2012a.

NUNES, T. S.; TOLFO, S. R. Políticas y prácticas de prevención y combate al acoso moral en una universidad brasileña. Salud de los Trabajadores, Valencia, v. 20, n. 1, p. 61-73, 2012b.
NUNES, T.; TOLFO, S.; NUNES, L. Assédio Moral em Universidade: a violência identificada por servidores docentes e técnico-administrativos. Revista Organizações em Contexto - Online, São Bernardo do Campo, v. 9, n. 18, p. 25-61, 2013.

RICHARDSON, R. J. et al. Pesquisa social: métodos e técnicas. São Paulo: Atlas, 2008.

SALIN, D. The prevention of workplace bullying as a question of human resource management: measures adopted and underlying organizational factors.

Scandinavian Journal of Management, Örebro, v. 24, n. 3, p. 221-231, 2008.

\section{SALIN, D. Workplace bullying among business} professionals: Prevalence, Organisational Antecedents and Gender Differences. Doctoral dissertation. Research Reports, Serie A, n. 117. Helsinki: Swedish School of Economics and Business Administration, 2003.

SCHATZMAM, M. et al. Aspectos definidores do assédio moral. In: GOSDAL, T. C.; SOBOLL, L. A. P. (Org.). Assédio moral interpessoal e organizacional: um enfoque interdisciplinar. São Paulo: LTr, 2009. p. 17-32.

SIEGLIN, V. El impacto del acoso laboral en los observadores. Estudios de caso en instituciones académicas en México. Revista Latino-Americana de Estudos do Trabalho, Rio de Janeiro, v. 17, n. 27, p. 191-223, 2012.

SOUZA, R. B.; AZEREDO, V. G. O assistente social e a ação competente: a dinâmica cotidiana. Revista Serviço Social e Sociedade, São Paulo, v. 15, n. 80, p. 48-58, 2004.

VARTIA, M. Workplace Bullying: A Study on the Work Environment. Well-Being and Health. Doctoral Dissertation. People and Work Research Reports 56. Helsinki: Finnish Institute of Occupational Health, 2003.

WARSHAW, L. J. Violence in the workplace. In: STELLMAN, J. M. (Ed.). Enciclopedia de salud y seguridad en el trabajo. Geneva: International Labour Office, 1998.

ZAPF, D.; EINARSEN, S. Mobbing at work: Escalated conflicts in Organizations. In: FOX, S.; SPECTOR, P. E. (Eds.). Counterproductive Work Behavior: investigations of actors and targets. Washington, DC: American Psychological Association, 2005. p. 237-270. 


\section{NOTAS}

1. Compreende-se, primeiramente, que se entende trabalho como um processo entre o homem e a natureza, onde o primeiro, por sua própria ação - através de uma atividade projetada, teleologicamente direcionada, conduzida a partir do fim proposto pelo sujeito -, media, regula e controla seu metabolismo com a natureza (MARX, 1982). Situa-se, portanto, que a história do capitalismo é marcada por distintas formas na relação entre os homens e a natureza, sendo que tal relação só pode ser compreendida se analisarmos como o homem organiza a produção dos meios de vida. Feito esse esclarecimento, entende-se o mundo do trabalho como "[...] o palco central da produção e da reprodução da vida material e, consequentemente, o espaço - seja no campo, na fábrica ou no setor de serviços - de intensa exploração dos trabalhadores que vendem sua força de trabalho. As relações precarizadas de trabalho tomaram proporções alarmantes no capitalismo contemporâneo, simultaneamente, o estranhamento intensificou-se no conjunto da vida social". (LARA, 2008, p. 2)

2. Há algumas questões que não respondidas, mas analisadas, neste caso, foram categorizados no item "Sem resposta".

3. É oportuno fazer uma ressalva de que ao contextualizar, de forma breve, o capitalismo no contexto latino-americano e enfatizar que a intensificação do assédio moral está estritamente vinculada à forma de organização da sociedade atual, não está se afirmando que o assédio moral é um fenômeno existente apenas nos países latino-americanos, mas sim, destacando que as vulnerabilidades sofridas pela classe trabalhadora nesses países são cada vez mais acentuadas e perversas.

4. Para Dejours (2007) e Heloani (2005), essa violência é algo intrínseco ao ser humano, assim como o amor, o ódio, o poder, a submissão, o orgulho, a inveja e as demais facetas da personalidade. 